\title{
Effect of vitrification on viability and chromosome abnormalities in 8-cell mouse embryos at various storage durations
}

\author{
HOSSEIN MOZDARANI ${ }^{1, *}$ and SHABNAM Z. MORADI ${ }^{2}$
}

\author{
${ }^{1}$ Department of Medical Genetics, School of Medical Sciences, Tarbiat Modares University, Tehran, P.O. \\ Box 14115-111, Iran. \\ ${ }^{2}$ Center for Research and Science, Islamic Azad Univ., and Royan Institute, Tehran, Iran.
}

\begin{abstract}
This study was designed to investigate the effect of vitrification and post-thaw survival and chromosomal aberrations caused by vitrification of vitrified 8-cell mouse embryos in comparison with a control group. To this purpose the survival rate and the frequency of chromosomal aberrations were assessed in frozen-thawed 8 -cell mouse embryos after various storage durations in the presence of ethylene glycol as cryoprotectant. Eight-cell mouse embryos were obtained from NMRI mice 3 days after mating. Retrieved embryos were transferred to vitrification solution containing ethylene glycol as cryoprotectant, then transferred into a vitrification straw using standard technique, and vitrified in liquid nitrogen. Six groups of embryos according to storage duration (24 hours, 1 and 2 weeks, 1-6 months) were frozen. After appropriate storage periods embryos were thawed and studied for their viability 4-6 hours after thawing and intact embryos were transferred to fresh medium containing colcemid. After 48 hours, the embryos were fixed and studied for their chromosome abnormalities using Tarkowsky's drying technique.

Results indicate that freezing affects the viability and chromosome structure of embryos when compared with the control group. Furthermore increasing the storage duration reduces the viability and increases the chromosome aberrations of embryos (such as aneuploidy and polyploidy).

This result might indicate that the effects of vitrification on the cytoskeleton or other cellular organelle might produce chromosomal alterations leading to cell death.
\end{abstract}

Key terms: Cryopreservation, vitrification, mouse embryo, viability, chromosome abnormalities.

\section{INTRODUCTION}

ARTs (Assisted Reproductive Technology) have become useful methods in alleviating infertility in childless couples and helping such couples obtain pregnancy. Excess embryos generated by these methods may be frozen for future replacement in an unstimulated cycle without the patients having to go through another treatment cycle. By storing embryos in liquid nitrogen, it is possible to transfer a limited number of embryos on successive occasions. This makes the best use of the embryos produced, reduces the number of attempts needed to retrieve oocytes, and reduces the chance of multiple pregnancies. Storing in liquid nitrogen also makes it possible to eliminate the risk of ovarian hyperstimulation syndrome (OHSS) because embryos can be transferred to patients in un-stimulated cycles (Mukaida et al. 1998).

Whittingham et al. (1971) first demonstrated the successful freezing of mouse embryos. The practical value of cryogenic preservation of embryos has been discussed elsewhere (Whittingham 1974). Freezing embryos, however, will be applicable only if high survival can be achieved, and if it can be shown that freezing of embryos has no detrimental effect on the subsequent ontogenic process.

\footnotetext{
* Corresponding author: Dr. Hossein Mozdarani; Department of Medical Genetics, School of Medical Sciences, Tarbiat Modares University, Tehran, P.O.Box 14115-111, Iran. Fax: (+98 21) 88006544. e-mail: Mozdarah@modares.ac.ir, Or, mozdarani_h@yahoo.com
} 
Technology for the long-term preservation of mammalian gametes and zygotes has improved greatly over the past 20 years (Bernard and Fuller 1996).

Various freezing methods are routinely used and newer methods are being developed via different researches. Methods which use cryoprotectant agents such as dimethyl sulphoxide (DMSO) and slow cooling to low subzero temperature (Whittingham 1971, Wilmut 1972), have been used with success for the cryopreservation of embryos from a wide range of species. The major disadvantage of the slow cooling method for routine application to embryos freezing is its time consuming nature. As a result, researches have been directed towards the development of faster and cheaper freezing methods. Therefore, we turned our attention to a vitrification protocol instead of the slow freezing method. Vitrification solutions are aqueous cryoprotectant solutions that do not form ice crystals when cooled at moderate rates to very low temperatures (Fahy et al. 1987) and thus avoid the potentially deleterious effects of intra-and extracellular ice crystals (Mazur 1984).

Some data strongly suggest that a large proportion of non-further cleaving embryos after a freezing and thawing cycle exhibit chromosomal abnormalities (Laverge et al. 1998). Another study suggests that blastomere fusion maybe an alternative mechanism by which human embryos acquire polyploidy, supported by the observation that blastomere fusion can be induced by freezing and thawing (Balakier et al. 2000). In contrast, according to a study, aneuploidy rates were low in both fresh and cryopreserved (slow freezing rapid thawing) embryos (Khromenkova et al. 2003).

Successful vitrification requires the use of a highly concentrated, effectively nontoxic solution of cryoprotectants (Rall and Fahy 1985). However, to achieve good survival after vitrification, embryos must be able to tolerate exposure and dehydration in these highly concentrated solutions (Rall 1987).

Our vitrification solution was based on the solution described by Kasai (1997). We studied the effect of vitrification on chromosome abnormalities of 8-cell mouse embryos. We evaluated the morphologic status of the embryos immediately after vitrification and after 4-6 hours post-thaw incubation and studied their viability and chromosomal status after thawing.

\section{MATERIALS AND METHODS}

\section{Source and recovery of embryos}

Female NMRI mice (Pasteur Institute; IRAN) aged 6-8 weeks were stimulated to ovulate using i.p. injections of 10 IU of pregnant mare serum gonadotropin (PMSG, Intervet, Netherland) followed by $10 \mathrm{IU}$ of human chorionic gonadotropin (hCG, Organon, Netherland) $48 \mathrm{~h}$ later. The females were mated singly with adult males from the same strain and were inspected the following morning for the presence of vaginal plug (day 1). At 67-68 h after hCG injection, the females were killed by cervical dislocation and 8-cell embryos were flushed from the removed oviducts with T6 medium [ingredients for a $\mathrm{pH}$ of 7.2-7.4; $\mathrm{NaCl}(4.73 \mathrm{mg} / \mathrm{ml}), \mathrm{KCl}(110 \mu \mathrm{g} /$ $\mathrm{ml}), \mathrm{NaH}_{2} \mathrm{PO}_{4}(50 \mu \mathrm{g} / \mathrm{ml}), \mathrm{MgCl}_{2} \cdot 6 \mathrm{H}_{2} \mathrm{O}$ $(100 \mu \mathrm{g} / \mathrm{ml}), \mathrm{CaCl}_{2} \cdot 2 \mathrm{H}_{2} \mathrm{O}(260 \mu \mathrm{g} / \mathrm{ml})$, $\mathrm{NaHCO}_{3}(2.10 \mathrm{mg} / \mathrm{ml})$, Phenol Red $(10 \mu \mathrm{g} /$ $\mathrm{ml})$, ethylenediamine-tetraacetic acid (EDTA, $6 \mu \mathrm{g} / \mathrm{ml})$, glucose $(1 \mathrm{mg} / \mathrm{ml})$ and Na-pyruvate $(30 \mu \mathrm{g} / \mathrm{ml})$ purchased from Sigma, USA; Penicillin G $(60 \mu \mathrm{g} / \mathrm{ml})$ and Streptomycin $(50 \mu \mathrm{g} / \mathrm{ml})$ from Seromed, Germany and Na-lactate $(1.98 \mu \mathrm{g} / \mathrm{ml})$ from Merck, Germany].

\section{Vitrification solution}

PB1 medium: Dulbecco's phosphate buffered saline (PBS) [ingredients; $\mathrm{CaCl}_{2}$, $2 \mathrm{H}_{2} \mathrm{O}(0.132 \mu \mathrm{g} / \mathrm{ml}), \mathrm{KCl}(200 \mu \mathrm{g} / \mathrm{ml})$, $\mathrm{KH}_{2} \mathrm{PO}_{4}(200 \mu \mathrm{g} / \mathrm{ml}), \mathrm{MgCl}_{2}(100 \mu \mathrm{g} / \mathrm{ml})$, $\left.\mathrm{NaCl}(8 \mathrm{mg} / \mathrm{ml}), \mathrm{Na}_{2} \mathrm{HPO}_{4}(1.15 \mathrm{mg} / \mathrm{ml})\right]$, modified with glucose $(5.56 \mathrm{mmol} / \mathrm{L})$, pyruvate $(0.33 \mathrm{mmol} / \mathrm{L})$, penicillin $\mathrm{G}(100$ $\mathrm{IU} / \mathrm{ml})$, streptomycin $(100 \mu \mathrm{g} / \mathrm{ml})$ and BSA (3 $\mathrm{mg} / \mathrm{ml})$.

Sucrose solution: PB 1 medium containing sucrose $(0.5 \mathrm{~mol} / \mathrm{L})$. 
FS solution: Fifteeng Ficoll 70 (mol wt $70,000)$ was added to $35.1 \mathrm{ml}$ filter sterilized PB1 medium, left overnight until the Ficoll dissolved thoroughly. Sucrose (8.56 g) was added and dissolved thoroughly. Then $105 \mathrm{mg}$ BSA was added and dissolved.

EFS40: $4 \mathrm{ml}$ ethylene glycol and $6 \mathrm{ml} \mathrm{FS}$ solution were added together in a $13 \mathrm{ml}$ test tube with a tight stopper, to make $40 \%(\mathrm{v} / \mathrm{v})$ ethylene glycol, $18 \%(\mathrm{w} / \mathrm{v})$ Ficoll and $0.3 \mathrm{M}$ sucrose. All materials used for preparing the vitrification solution were purchased from Sigma Co., USA, except ethylene glycol that was from Aldrich, USA.

\section{Vitrification of mouse embryos}

The vitrification procedure was similar to that described by Kasai (1997). The room temperature was adjusted in order to equilibrate the instruments and all the solutions at $25^{\circ} \mathrm{C}$.

Embryos were directly suspended in the vitrification solution at room temperature in a watch glass. 2 min after exposure of the embryos to a vitrification solution, they were collected and embryos were loaded directly to straws, 10 to each.

The configuration of the straw was described previously (Kasai 1997). In this research according to the storage duration we had 6 groups: 6 months, 3 months, 1 month, 2 weeks, 1 week and 24 hours. Then straws were plunged into liquid nitrogen. A total of 350 embryos were frozen and studied for each group. It should be mentioned that the level of liquid nitrogen was assessed by a special ruler that was specified for the nitrogen tank, and once a week, the level of liquid nitrogen was tested to ensure that it covered the surface of the canisters. In addition, for every group, there was a specific canister. It means, for example, the canister of " 6 months" group was separated from other groups and removing a canister, didn't cause warming of the other canisters.

\section{Thawing and cryoprotectant dilution}

After specified storage duration (24hours, 1 week, 2 weeks, 1 month, 3 months, 6 months), embryos were thawed. For thawing, straws were taken out of liquid nitrogen and immediately plunged into water at $25^{\circ} \mathrm{C}$. After $10 \mathrm{sec}$, the straws were removed from the water, quickly wiped dry and the contents of the straws were expelled into a watch glass containing $0.8 \mathrm{ml}$ of sucrose solution, by cutting the cotton plug with scissors. After about 1 min the embryos were pipetted into a fresh sucrose solution for 3-4 min.

Assessment of viability of vitrified mouse embryos

Embryos recovered after vitrification were washed and cultured in warm T6 medium (containing $4 \mathrm{mg} / \mathrm{ml}$ BSA) under paraffin oil in a culture dish, in an incubator at $37^{\circ} \mathrm{C}$, in an atmosphere of $5 \% \mathrm{CO}_{2}$ in air. Within 4-6 hours the embryos were assessed for their morphological appearance under a stereomicroscope (Hund-Wetzlar, Germany) and their viability was determined.

\section{Chromosome analysis}

After 4-6 hour in T6 medium, first, the embryos were plunged in acid Tyrode's solution for 7 seconds in 3 steps to slenderize zona pellucida, then the embryos were exposed to the T6 medium containing colcemid for 48 hours; after that embryos were placed in hypotonic solution (1\% sodium citrate in water) until swollen (3-15 min). The swollen embryos were individually placed on clean glass microscope slide in a minimal amount of fluid and then spread using the fixation solution described previously by Tarkowski (1966). The slides were stained with Giemsa $(3 \%)$, and examined under a light microscope (Nikon E800, Japan) at $\times 1000$ magnification for numerical chromosome analysis.

\section{Statistical Analysis}

Survival rates of 6 groups were analyzed using the $\chi^{2}$ test. Chromosome abnormalities were analyzed by $\chi^{2}$ test and Fisher test to determine the effect of vitrification on chromosomal abnormalities at various storage durations. These analyses were done with SPSS software. 


\section{RESULTS}

\section{Viability}

The viability rates for frozen embryos in the 6 groups are summarized in table 1. As seen, by increasing storage duration, viability percentage decreases. For example, in "24 hour" group this value is $90.1 \%$ and in "6 months" group is $15.8 \%$ (Table 1 and Fig. 1).

There is a decrement from control group to 6 months group; although there is not a significant difference in 1 and 2 week groups compared to control.

\section{Chromosome abnormalities}

The number of embryos showing chromosome abnormalities (aneuploidy and polyploidy), are summarized in table 2. As indicated, increasing storage duration, increases the incidence of aneuploidy and polyploidy. In figure 1 there is an upward trend from control group $(16.7 \%)$ to 6 month group. It reached a plateau in 1 and 2 week group at $42.2 \%$ and $43.6 \%$. The incidence of abnormality in 6 months group was the highest comparing to control group $(P<0.001)$. There are significant differences of aneuoploidy between the test and control

TABLE 1

The result of post-thaw viability of embryos frozen for different time intervals

\begin{tabular}{lcccc}
\hline $\begin{array}{l}\text { Parameters/ } \\
\text { Test groups }\end{array}$ & Total embryos & Total intact embryos & Total degenerate embryos & Viability (\%) \\
\hline Control & 60 & 59 & 1 & 98.3 \\
24 hrs & 354 & 319 & 35 & 90.1 \\
1 week & 360 & 302 & 58 & 83.9 \\
2 weeks & 360 & 297 & 63 & 82.5 \\
1 month & 360 & 285 & 75 & 79.2 \\
3 months & 355 & 162 & 193 & 45.6 \\
6 months & 355 & 56 & 299 & 15.8 \\
\hline
\end{tabular}

TABLE 2

The result of total chromosomal abnormalities seen in embryos frozen for various storage durations

\begin{tabular}{lccccc}
\hline $\begin{array}{l}\text { Parameters/ } \\
\text { Test groups }\end{array}$ & $\begin{array}{c}\text { Analyzed } \\
\text { metaphases }\end{array}$ & $\begin{array}{c}\text { Aneuploid* } \\
\text { embryos }\end{array}$ & $\begin{array}{c}\text { Hyperdiploid** } \\
\text { embryos }\end{array}$ & $\begin{array}{c}\text { Polyploid*** } \\
\text { embryos }\end{array}$ & $\begin{array}{c}\text { Normal } \\
\text { embryos }\end{array}$ \\
\hline Control & 60 & 5 & 0 & 1 & 54 \\
24 hrs & 31 & 10 & 0 & 1 & 20 \\
1 week & 34 & 9 & 1 & 4 & 20 \\
2 weeks & 39 & 10 & 4 & 3 & 22 \\
1 month & 38 & 10 & 3 & 5 & 16 \\
3 months & 39 & 16 & 7 & 12 & 4 \\
6 months & 39 & 18 & 5 & & 4 \\
\hline
\end{tabular}

\footnotetext{
* Aneuploid embryos: The embryos whose chromosome count was 37-43.

** Hyperdiploid embryos: The embryos whose chromosome count was 44-76.

*** Polyploid embryos: The embryos whose chromosome count was 77-83.
} 


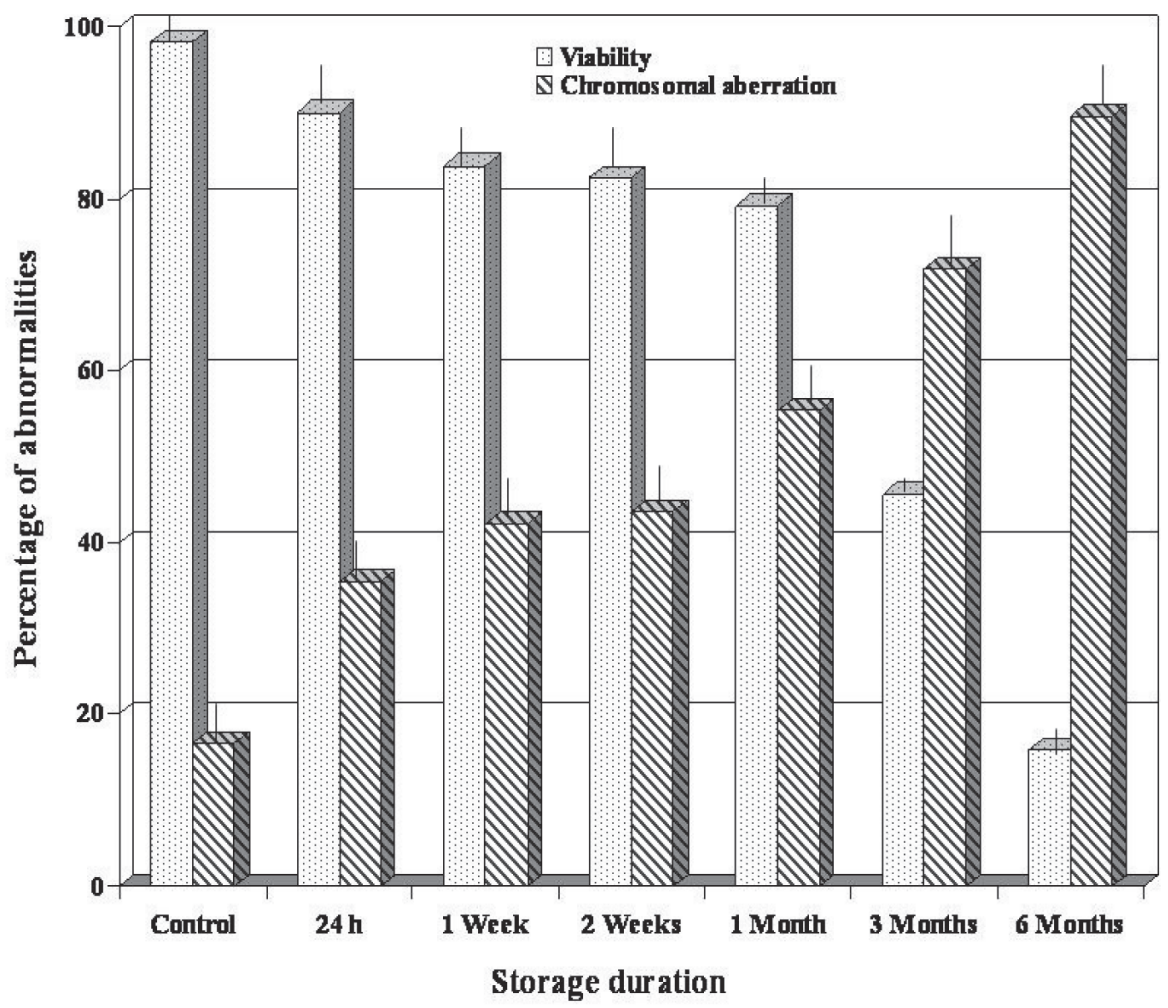

Figure 1: Percentage of viability and total chromosomal abnormalities including polyploidy in embryos kept frozen in the presence of ethylene glycol as cryoprotectant for various storage durations. Error bars show SE of mean values calculated for data obtained from different samples.

group. According to figure 1, compared to control group there was a significant difference in total abnormalities rate of 24 hour, 1 week, 2 weeks, 1 month, 3 month and 6 month group (all $P$-values were $<0.001$ ) (Table 2, Fig. 1).

\section{DISCUSSION}

\section{Freezing viability}

Storage duration was found to be the most important factor in freezing 8-cell mouse embryos. According to our results increasing the storage duration caused a decreased post-thaw survival of 8-cell mouse embryos (Table 1, Fig. 1).

Multiple factors, such as stimulation protocols, freezing procedure and embryo quality at freezing may influence the success of an embryo freezing program $(\mathrm{Hu}$ et al. 1999).

The freezing and warming of cells imposes a concatenation of stresses including equilibrating with a cryoprotectant, cooling, warming, dilution and rehydration (Cohen 1992). However, freezing and thawing significantly reduces embryo viability (Selick et al. 1995). Some embryos do not survive freezing and thawing, and in some cases the majority of blastomeres undergo degeneration (Whittingham 1974). The adverse effects of cryopreservation may also lead to the formation of cracks in the zona pellucida, or injuries to the cell membranes and intracellular components ( $\mathrm{Ng}$ et al. 1988, Dumoulin et al. 1994). In some other studies, protective polymers (Dumoulin et 
al. 1994, Titterington and Robinson 1996) or host zonae (Niemann 1991) have been shown to improve cryosurvival rates. Ideally the freeze-thaw procedure should not cause any loss of viability, or lead to an increased incidence of genetic aberrations, fetal malformations or losses. Several lines of evidence suggest that the damage may be more closely linked to the freezing properties of cryoprotectant solution (Bongso et al. 1988, Herskovits and Harrington 1972).

Intracellular ice is more likely to be formed when the permeation of the cryoprotectant and its concentration in the cytoplasm are insufficient.

Mohr and Trounson (1981) concluded that cryoinjury to embryos may be selective for one cell type within an embryo, and the extent and nature of damage was dependent on the developmental stage. Another research suggests that excellent quality embryos, frozen and thawed at the 8- to 16-cell stage, often do not develop in vitro without full protection of an intact zona pellucida. For early stage embryos, it is thought that the zona pellucida helps to maintain cellular integrity of the blastomerees (Vital and Myers 1997). Artificially induced alterations in the integrity of the zona pellucida may affect subsequent embryo cleavage, compaction, blastocyst formation and zona hatching of human embryos (Cohen 1992).

The results of our experiment demonstrate that there is a possibility of zona injury that may reduce post-thaw viability; furthermore increased storage duration causes reduced viability that can be due to cryprotectant permeating or as mentioned, zona pellucida damages. Our results are in line with the recent report of Coutinho et al. (2007) who compared two methods of cryopreservation by assessing morphological alterations of frozen embryos using light, fluorescence, and transmission electron microscopy. They have clearly shown that vitrification caused more membrane permeability, more severe cellular alterations and reduced embryonic viability compared to a slow freezing method.

\section{Chromosome abnormalities}

We have shown that vitrification in solution containing ethylene glycol can cause severe chromosomal aberrations and reduced embryo viability in vitro. The incidence and severity of the damage is influenced by the storage duration (Table 2, Fig 1). The highest incidence of chromosomal aberrations occurred among embryos in the "6 month" group. These damages appear more closely linked to factors such as ice crystal formation during storage duration in vitrification. Cryopreserved oocytes exhibited serious disturbances of the microtubules immediately after thawing. Fertilization of oocytes with disorganized spindles could lead to chromosomal aneuploidy, disgeny, and arrest of cleavage (Chen et al. 2003). It is known that the cytoskeleton of mammalian oocytes and embryos is thermo- and chemo-sensitive and sensitive to stresses connected with cryopreservation (Pickering and Johnson 1987, Sathananthan et al. 1988, Vander et al. 1988). Disorganization of spindle after cryopreservation was observed in metaphase II oocytes and late 2-cell embryos in mitosis (Sathananthan et al. 1988).

The unequal distribution of chromosomes, between daughter cells results in aneuploidy at multipolar mitosis or in a polyploid unipolar mitosis (Khromenkova et al. 2003). It is known that aneuploidy is one of the causes of low implantation rate and early embryonic mortality in mammalian species (Bongso et al. 1988)

In some reports major chromosomal anomalies such as trisomy of chromosome 13,18 and 21, as well as major and minor congenital malformations, have been identified in fetuses and babies conceived from frozen embryos (Sutcliffe et al. 1995, Wennerholm et al. 1997). On the other hand, a comparison of babies resulting from the transfer on frozen-thawed embryos with those conceived normally or from fresh IVF cycles showed a similar or even decreased incidence of congenital abnormalities after cryopreservation (Wada et al. 1994, Wood 1997). 
A study of aneuploidy and mosaicism of chromosomes $\mathrm{X}, \mathrm{Y}$ and 1 in human frozen embryos (day 2 and 3 of development) using fluorescence in situ hybridization (FISH) showed that a large proportion of thawed embryos (57\%) exhibiting cleavage arrest during the first $24 \mathrm{~h}$ of in vitro culture carried numerical chromosomal abnormalities (Hu et al. 1999). However, it remains uncertain whether those aberrations were induced by the cryopreservation technique, or were already present in chromosomally abnormal embryos, before thawing. Several reports on mouse embryos have shown that vitrification may cause some chromosomal damage (Show and Kola 1991) or increased mitotic crossing over (Bongso et al. 1988, Ishida et al. 1997).

From our study, it seems that freezing and thawing is responsible for blastomere fusion. According to our results blastomere fusion is not only attributed to fair and poor quality embryos, as was previously thought (Trounson 1984) but it can also affect morphologically sound embryos, as was shown by our observation (all embryos were of good quality) (Balakier et al. 2000). The general studies have proven that a defect in the cell membrane is required for initiation of fusion, which can be induced by many membrane disrupting agents such as a virus, polyethylene glycol or electric field, as well as freezing and thawing (Hui et al. 1981, Zimmermann 1996). Based on these reports, it seems that cryoprotectants may also contribute to the process of fusion by causing cell dehydration and osmotic swelling which induce other changes that are necessary to induce fusion (for instance, changes in the cytoskeleton, tight contact between cells, etc).

This study has demonstrated that vitrification of mouse embryos using ethylene glycol as cryoprotectant can lead to induction of chromosomal aberrations. In addition, rapid cooling, warming and dilution solutions can cause the problem of injury to the zona pellucida which is very sensitive to cryoprotectants and low temperature. However, the morphological survival rate of embryos was reduced by increasing storage duration. The reason for this is not clear, but may be attributed to the ice crystal formation during freezing and sudden extremes of cooling. Further research is warranted to improve the long term survival and preservation of the chromosomes in embryo vitrification using ethylene glycol as cryoprotectant.

\section{ACKNOWLEDGEMENT}

This research was partly supported by Royan Institute.

\section{REFERENCES}

口BALAKIER H, CABACA O, BOUMAN D, SHEWCHUK AB, LASKIN C, SQUIRE JA (2000) Spontaneous blastomere fusion after freezing and thawing of early human embryos leads to polyploidy and chromosomal mosaicism. Hum Reprod 15: 2404-2410

BERNARD A, FULLER BJ (1996) Cryopreservation of human oocytes: a review of current problems and perspectives. Hum Reprod Update 2: 193-207

BONGSO A, CHYE NS, SATHANANTHAN H, MUI-NEE L, MOK H, WONG PC, RATNAM S (1988) Chromosome analysis of two cell embryos frozen by slow and ultrarapid methods using two different cryoprotectants. Fertil Stril 49: 908-912

CHEN SU, LIEN YR, CHAO KH, HO HN, YANG YS, LEE TY (2003) Effects of cryopreservation on meiotic spindles of oocytes and its dynamics after thawing: clinical implications in oocytes freezing - a review article.; Mol Cell Endocrinol 202: 101-107

COHEN J (1992) Zona pellucida micromanipulation and consequences for embryonic development. In Cohen J, Malter HE, Talansky BE, Grifo J (eds), Micromanipulation of human gametes and embryos. Raven press, New York; pp: 191- 222

COUTINHO AR, MENDES CM, CAETANO HV, NASCIMENTO AB, OLIVEIRA VP, HERNADEZBLAZQUEZ FJ, SINHORINI IL, VISINTIN JA, ASSUMPÇÃO ME (2007) Morphological changes in mouse embryos cryopreserved by different techniques. Microsc Res Tech 70: 296-301

DUMOULIN JC, BERGERS-JANSSEN JM, PIETERS MH, ENGINSU ME, GERAEDTS JP, EVERS JL (1994) The protective effects of polymers in the cryopreservation of human and mouse zona pellucida and embryos. Fertil Stril 62: 793-798

FAHY GM, LEVY DI, ALI SE (1987) Some emerging principles underlying the physical properties, biological actions, and utility of vitrification solutions. Cryobiology 24: 196-231

HERSKOVITS TT, HARRINGTON JP (1972) Solution studies of the nucleic acid bases and related model compounds. Solubility in aqueous alcohol and glycol solutions. Biochemistry NY 11: 4800-4810

HU Y, MAXSON WS, HOFFMAN DI, ORY SJ, EAGER S (1999) A comparison of post- thaw results between cryopreserved embryos derived from intracytoplasmic sperm injection and those from conventional IVF. Fertil Steril 72: 1045-1048 
HUI SW, STEWART TP, BONI LT, YEAGLE PL (1981) Membrane fusion through point defect in bilayers, Science 212: 421-423

ISHIDA GM, SAITO H, OHTA N, TAKAHASHI T, ITO MM, SAITO T, NAKAHARA K, HIROI M (1997) The optimal equilibration time for mouse embryos frozen by vitrification with trehalose. Hum Reprod 12: 12591262

KASAI M (1997) Cryopreservation of mammalian embryos. Mol Biotech 7: 173-179

KHROMENKOVA OB, ZHERNOKLEV GV, ZHEGUNOV GV, GRISCHENKO VF (2003) The incidence of mitotic abnormalities in cryopreserved eight-cell early and compacted mouse embryos. Cryo Letter 24: 27-32

LAVERGE H, VAN DER ELST J, DE SUTTER P, VERSCHRAEGEN-SPAE MR, DE PAEPE A, DHONT M (1998) Fluorescent in situ hybridization on human embryos showing cleavage arrest after freezing and thawing. Hum Reprod 13: 425-429

MAZUR P (1984) Freezing of living cells: Mechanism and implications. Am J Physiology 247: (Cells Physiology 16: c 125- c142)

MOHR LR, TROUNSON A (1981) Structural changes associated with freezing of bovine embryos. Biol Reprod 25: 1009

MUKAIDA T, WADA S, TAKAHASHI K, PEDRO PB, AN TZ, KASAI M (1998) Vitrification of human embryos based on assessment of suitable conditions for 8cell mouse embryos. Hum Reprod 13: 2874-2879

NG SC, SATHANANTHAN AH, WONG PC, RATNAM SS, HO J, MOK H, LEE MN (1988) Fine structure of early human embryos frozen with 1,2 propanediol. Gamete Res 19: 253-263

NIEMANN H (1991) Cryopreservation from live stock: current status and research needs. Theriogenology 35: $109-124$

PICKERING SJ, JOHNSON MH (1987) The influence of cooling on the organization of the meiotic spindle of the mouse oocyte. Hum Reprod 2: 207-216

RALL WF, FAHY GM (1985) Ice free cryopreservation of mouse embryos at $196^{\circ} \mathrm{C}$ by vitrification. Nature 313: 573-575

RALL WF (1987) Factors affecting the survival of mouse embryos cryopreserved by vitrification. Cryobiology 24: $387-402$

SATHANANTHAN AH, NG SC, TROUNSON AO, BONGSO A, RATNAM SS, HO J, MOK H, LEE MN (1988) The effects of ultrarapid freezing on meiotic and mitotic spindles of mouse oocytes and embryos. Gamete Res 21: 385-401

SELICK CE, HOFMANN GE, ALBANO C, HOROWITZ GM, COPPERMAN AB, GARRISI GJ, NAVOT D (1995) Embryo quality and pregnancy potential of fresh compared with frozen embryos: is freezing detrimental to high quality embryos? Hum Reprod 10 392-395

SHOW JM, KOLA I (1991) An association between chromosome abnormalities in rapidly frozen 2 -cell mouse embryos and the ice-forming properties of the cryoprotective solution. J Reprod Fertil 91: 9-18

SUTCLIFFE AG, D'SOUZA SW, CADMAN J, RICHARDS B, MCKINLAY IA, LIEBERMAN B (1995) Minor congenital anomalies, major congenital malformations and development in children conceived from cryopreserved embryos. Hum Reprod 10: 3332 3337

TARKOWSKI AK (1966) An air drying method for chromosome preparations from mouse eggs. Cytogenetics 5: 394-400

TITTERINGTON JL, ROBINSON J (1996) The protective action of polyvinyl-pyrolidone-percoll during the cryopreservation of mouse 2 - cell embryos and its effect on subsequent developmental potential postthaw in vitro and in vivo. Hum Reprod 11: 2697- 2702

TROUNSON A (1984) In vitro fertilization and embryo preservation. In Trounson A and wood C (eds), In vitro fertilization and embryo Transfer. Churchill Livigstone, Edinburgh; pp: 111-130

VAN DER ELST J, VAN DEN ABBEEL E, JACOBS R, WISSE E, VAN STEIRTEGHEM A (1988) Effect of 1,2- propanediol and dimethylsulphoxide on the meiotic spindle of the mouse oocyte. Hum Reprod 3: 960-967

VITAL NJ, MYERS MW (1997) In vitro development of refrozen embryos. Hum Reprod 12: 310-316

WADA I, MACNAMEE MC, WICK K, BRADFIELD JM, BRINSDEN PR (1994) Birth characteristics and prenatal outcome of babies conceived from cryopreserved embryos. Hum Reprod 9: 543-546

WENNERHOLM UB, HAMBERGER L, NILSSON L, WENNERGREN M, WIKLAND M, BERGH C (1997) Obstetric and prenatal outcome of children conceived from cryopreserved embryos. Hum Reprod 12: 18191825

WHITTINGHAM DG (1971) Survival of mouse embryos after freezing and thawing. Nature (Lond) 233: 125126

WHITTINGHAM DG (1974) The viability of frozenthawed mouse blastocysts. J Reprod Fertil 37: 159-162

WILMUT I (1972) The effect of cooling rate, warning rate, cryoprotective agent and stage of development on survival of mouse embryos during freezing and thawing. Life Sci 11: 1071-1079

WOOD MJ (1997) Embryo freezing: is it safe? Hum Reprod 12, JBFS 2(1): Natl suppl, 32-37

ZIMMERMANN U (1996) Electro fusion of cells: State of the art and future directions. In Zimmermann U. and Neil G.A. (eds), Electro manipulation of cells. CRC Press, Boca Raton, New York, pp: 173-257 